Research Article

\title{
Estimation of Soil-Water Characteristic Curve for Cohesive Soils with Methylene Blue Value
}

\author{
Junhui Zhang $\mathbb{D}^{1},{ }^{1}$ Junhui Peng $\mathbb{D}^{1},{ }^{1}$ Yejuan Chen, ${ }^{2}$ Jue Li, ${ }^{1}$ and Feng $\mathrm{Li}^{1}$ \\ ${ }^{1}$ National Engineering Laboratory of Highway Maintenance Technology, Changsha University of Science and Technology, \\ Changsha 410114, China \\ ${ }^{2}$ Changsha Commerce and Tourism College, Changsha 410001, China
}

Correspondence should be addressed to Junhui Peng; q376689004@163.com

Received 1 March 2018; Accepted 10 June 2018; Published 5 July 2018

Academic Editor: Qiang Tang

Copyright ( $\odot 2018$ Junhui Zhang et al. This is an open access article distributed under the Creative Commons Attribution License, which permits unrestricted use, distribution, and reproduction in any medium, provided the original work is properly cited.

\begin{abstract}
This study described a new methylene blue test to measure the methylene blue value (MBV) for 15 cohesive soils and established the relationship between MBV and plasticity index (PI) and between MBV and percent passing No. 200 sieve $\left(\mathrm{P}_{200}\right)$, respectively. Thereafter, the soil-water characteristic curves (SWCCs) for 15 cohesive soils based on Fredlund and Xing's model were generated by the pressure plate test. Then, regression equations for determining the four fitting parameters in a previously developed SWCC equation by using the measured MBV were utilized to generate the SWCC for the cohesive soils. At the same time, the slope parameter, $b_{\mathrm{f}}$, in the SWCC equations was found to be associated with the moisture susceptibility of cohesive soils. A higher $b_{\mathrm{f}}$ value indicates that the material is more moisture susceptible. In addition, a lower $\mathrm{MBV} / \mathrm{PI} / \mathrm{P}_{200}$ shows a lower suction at the same degree of saturation; on the other hand, a higher $\mathrm{MBV} / \mathrm{PI} / \mathrm{P}_{200}$ presents a higher suction. Therefore, the moisture-holding capacity of cohesive soils increases with increasing MBV, PI, and $\mathrm{P}_{200}$. Finally, the proposed estimation method was validated by a comparison between the four determined fitting parameters from $\mathrm{MBV}$ and the pressure plate test.
\end{abstract}

\section{Introduction}

The soil-water characteristic curve (SWCC) is a graphical relationship between the matric suction and the water content. It is one of the basic characteristics of partially unsaturated soils, and as such, it is useful for estimating the other properties of soil, when solving engineering problems in these three classic areas: fluid flow, compressibility, and shear strength [1]. For example, when modeling unsaturated moisture flow beneath a highway pavement, the hydraulic conductivity of the base course and subgrade materials, as a function of moisture content, must be known. Since the experimental procedures, in which a filter paper or pressure plate test, adopted for determining the matric suction-water content relationship, is time-consuming and cost-intensive $[2,3]$, recent research has placed a major focus on an estimation method to predict the SWCC using some mathematical functions $[1,4,5]$. However, the shape of the curve depends on many basic soil properties, such as the percent passing No. 200 sieve $\left(\mathrm{P}_{200}\right)$, plasticity index $(\mathrm{PI})$, and environmentally induced factors that determine the stress state, compaction level, and temperature. It is difficult to find a valid and convenient mathematical expression to describe it. However, several analytical functions for predicting the SWCC can be found in some literatures [6-9]. The predicting variables, including sieve analysis and index properties, display extensive variability in those literatures [10]. Some time-consuming and material-consuming experiments are still necessary, including sieve analysis and Atterberg limits. Under this circumstance, Hakan Sahin et al. proposed a new estimation method to determine SWCC for unbound aggregate mixtures based on the methylene blue value (MBV) and percent fines content (PFC) [11-13].

The methylene blue has a large polar organic molecule $\mathrm{C}_{16} \mathrm{H}_{18} \mathrm{~N}_{3} \mathrm{~S}^{+}$that can be adsorbed onto the negatively charged surfaces of clay minerals. The amount of adsorbed methylene blue depends on the amount of the surface area of the clay particles. The more the methylene blue adsorbed by 
the clay particles, the brighter the methylene blue solution will be. The adsorbed methylene blue is able to be quantified by assessing the color change of the methylene blue solution. At the same time, SWCCs for cohesive soils reveal their waterholding capacity which depends on the specific surface area of the clay particles $[9,14-18]$. Based on the above description about the methylene test, MBV reflects the specific surface area of soil particles. Therefore, SWCCs for cohesive soils can be predicted using the methylene blue value. Once the relationship between the four fitting coefficients of Fredlund and Xing's model, which are shown in (1), and the MBV is built, SWCCs for cohesive soils will be determined:

$$
\begin{aligned}
\theta_{\omega} & =C(h) \times \frac{\theta_{\mathrm{s}}}{\left\{\ln \left[\exp (1)+\left(h / a_{\mathrm{f}}\right)^{b_{\mathrm{f}}}\right]\right\}^{c_{\mathrm{f}}}}, \\
C(h) & =1-\frac{\ln \left(1+\left(h / h_{\mathrm{r}}\right)\right)}{\ln \left(1+\left(10^{6} / h_{\mathrm{r}}\right)\right)},
\end{aligned}
$$

where $\theta_{\omega}$ is the volumetric water content; $\theta_{s}$ is the saturated volumetric water content; $h$ is the matric suction; and $a_{\mathrm{f}}, b_{\mathrm{f}}, c_{\mathrm{f}}$, and $h_{\mathrm{r}}$ are fitting coefficients, which are primarily a function of the air entry value, rate of water extraction from the soil, residual water content, and suction at which the residual water content occurs, respectively. Once these four fitting parameters are determined, the SWCC for a specific soil can be established automatically.

This study is organized as follows: The forthcoming section introduces a new methylene blue test method, and the methylene blue tests of 15 cohesive soils were completed. Subsequently, the correlation between PI and MBV and between $\mathrm{P}_{200}$ and $\mathrm{MBV}$ was proposed and analyzed, respectively. The next section builds the correlations between the four fitting parameters of Fredlund and Xing's model and the MBV, which were validated subsequently. The final section summarizes the major findings of this study.

\section{Experiments and Materials}

Based on the preceding discussions, this section presents the laboratory experiments and materials required to develop the fitting models for the SWCCs.

2.1. Laboratory Experiments. The sieve test and Atterberg limit test were employed to determine the particle distribution and plasticity index, respectively. At the same time, the maximum dry density and optimum moisture content, which were utilized to mold the soil samples for the pressure plate test, were gained according to the Proctor test. Thereafter, the pressure plate test was used to measure the matric suction for different moisture contents. In addition, the methylene blue test was used to detect the amount of fine particles in 15 cohesive soils. The pressure plate test and methylene blue test are briefly introduced in the following sections.

2.2. New Methylene Blue Test. A traditional methylene blue test, specified in ASTMC837 [19], was used to determine the active clay content in fine materials by measuring the methylene blue dye content adsorbed by clay particles. This traditional test method contains an empirical check criterion, in which the test procedures need to be repeated until a light blue ring is found. It is time-consuming and requires experienced personnel to operate the test, which is similar to the method of the current specification of Test Methods of Aggregate for Highway Engineering in China. Recently, a new test method, which measures the MBV of soils by using the methylene blue solution with a colorimeter, was proposed by W.R. Grace Inc. The advantage of this new test method is that it is relatively simple, inexpensive, and repeatable. Figure 1 shows the apparatus which consists of a colorimeter, a $150 \mu \mathrm{L}$ pipette with a resolution of $1 \mu \mathrm{L}$, a dropper, a $3 \mathrm{~mL}$ syringe, two $50 \mathrm{~mL}$ plastic bottles, two sample bottles, methylene blue solution, and distilled water. In addition, a $0.20 \mu \mathrm{m}$ filter of the syringe, a portable balance with a resolution of $0.01 \mathrm{~g}$, a standard sieve, and a small glass tube are also needed.

Firstly, the sample was passed through a $2 \mathrm{~mm}$ sieve, and $20.00 \mathrm{~g}$ sample was taken as the initial amount. The sample was added to a plastic bottle with $30.00 \mathrm{~mL}$ calibrated methylene blue solution. The mixture was shaken for $1 \mathrm{~min}$, rested for $3 \mathrm{~min}$, and shaken again for 1 more min. Thereafter, the mixture was filtered through a $2.0 \mu \mathrm{m}$ filter by using a syringe. And the mixture passing the filter was used for the rest of the experiment. Subsequently, $30.00 \mathrm{~mL}$ of the filtered solution was added to a plastic bottle and filled with distilled water until a total of $45.00 \mathrm{~g}$ is collected. The newly mixed solution was put into a small glass tube plugged into the colorimeter, and the MBV can be measured by using the colorimeter. It is considered that $20.00 \mathrm{~g}$ is a valid sample amount, and the value of reading is valid, if the MBV reading is smaller than $7.50 \mathrm{mg} / \mathrm{g}$. The sample size must be halved to $10.00 \mathrm{~g}$, and the test procedure should be repeated, if the $\mathrm{MBV}$ is higher than $7.50 \mathrm{mg} / \mathrm{g}$. It is worth mentioning that the total test time for a measurement is less than $10 \mathrm{~min}$. The methylene blue value ( $\mathrm{mg} / \mathrm{g}$ ) can be calculated by (2) after the methylene blue tests were completed:

$$
\mathrm{MBV}=\frac{\left(C_{\mathrm{i}}-C_{\mathrm{f}}\right) \times M_{\mathrm{MB}}}{M_{\mathrm{FM}}} \times 1000 \mathrm{mg} / \mathrm{g},
$$

where $C_{i}$ is the initial concentration of the methylene blue solution; $C_{\mathrm{f}}$ is the final concentration of the methylene blue solution; $M_{\mathrm{MB}}$ is the weight of the methylene blue solution; and $M_{\mathrm{FM}}$ is the weight of the soil samples. The average value of three tests for one soil is selected as the final MBV.

Table 1 shows the soil amount and the corresponding valid MBV range. It should be noted that the method using the methylene blue solution with a colorimeter is not suitable for soils in the case that the MBV is larger than $60 \mathrm{mg} / \mathrm{g}$. For this case, the traditional method to measure the MBV should be adopted $[19,20]$.

2.3. Pressure Plate Test. The pressure plate consists of a highpressure nitrogen gas bottle, a reducing valve, a pressure cooker, a ceramic plate, and so on, which is used to measure both matric and total suction with respect to the moisture 


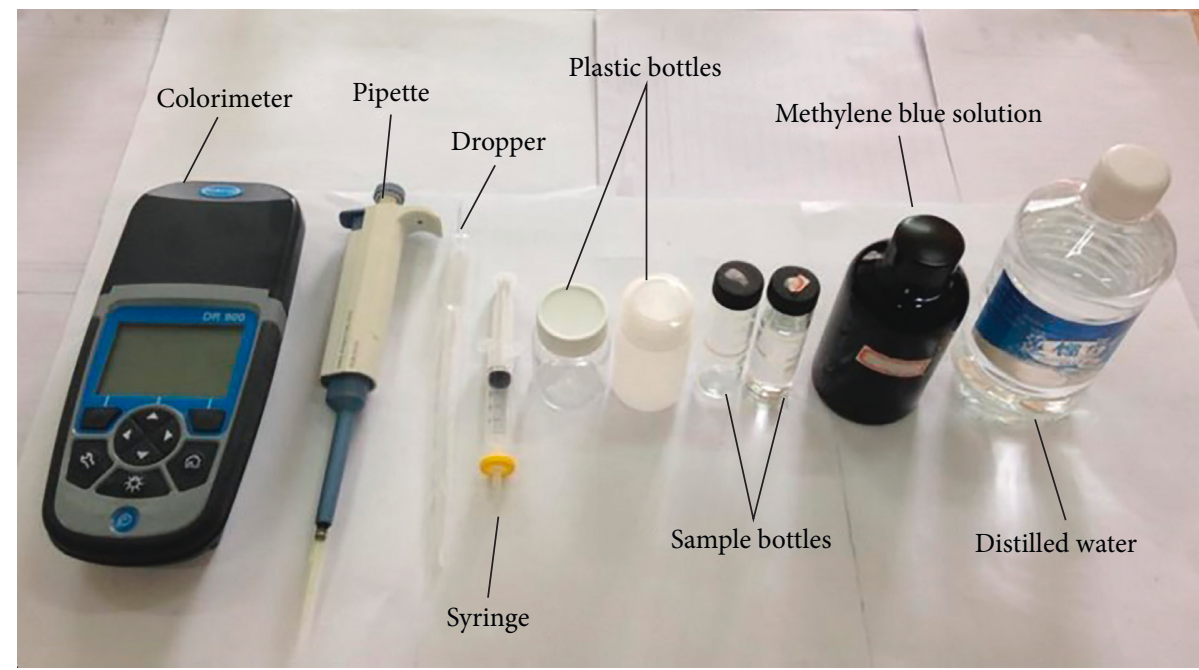

Figure 1: Apparatus.

TABLE 1: Soil amount and corresponding valid MBV range.

\begin{tabular}{lc}
\hline Soil weight $(\mathrm{g})$ & MBV range $(\mathrm{mg} / \mathrm{g})$ \\
\hline 20 & $0<\mathrm{MBV}<7.5$ \\
10 & $7.5 \leq \mathrm{MBV}<15$ \\
5 & $15 \leq \mathrm{MBV}<30$ \\
2.5 & $30 \leq \mathrm{MBV}<60$ \\
\hline
\end{tabular}

content of the sample. For this test, soil samples of $618 \mathrm{~mm}$ diameter and $100 \mathrm{~mm}$ height were made by a cutting ring at compacted degree of $90 \%$ and at the optimum moisture content. Then, the samples were put into a vacuum saturator and were taken out 48 hours later for equilibrating the internal moisture content. Thereafter, the mass was recorded when there is no water on the surface of samples. Subsequently, the ceramic plate was put into the pressure cooker and saturated. The following step was to put the saturated sample into the pressure plate and add air pressure until reaching a balanced state. After that, the moisture content of the sample was measured and the pressure was read. By repeating the above steps, the SWCC for the soil sample can be developed.

2.4. Materials. Fifteen cohesive soils were taken from different field sites of Hunan Province in this study, which is located in South China [21]. Table 2 summarizes the results for laboratory testing. Since the MBV of the soil samples S13 and S14 is larger than $60 \mathrm{mg} / \mathrm{g}$, it was measured by the traditional method $[19,20]$.

\section{Correlations between MBV and PI and between $P_{200}$ and $M B V$}

The four fitting coefficients of Fredlund and Xing's model can be predicted by $\mathrm{P}_{200}$ and PI, based on the available database. Thus, it is necessary to analyze the relationship between the MBV and PI and between MBV and $\mathrm{P}_{200}$, respectively. Figure 2 presents the relationship between the MBV and PI for the selected cohesive soils and the solid line represents a trend line. A correlation equation is observed between PI and MBV, as shown in (3). Witczak et al. [22, 23] suggested subjective criteria for goodness predictions based on the coefficient of determination $\left(R^{2}\right)$ values. An excellent fit can be defined as $R^{2} \geq 0.9$, a good fit covers the $\mathrm{R}^{2}$ range of $0.7-0.89$, and a fair fit is defined as $0.4 \leq R^{2} \leq 0.69$. Therefore, (3) is a good fit for selected cohesive soils and can provide a relatively satisfactory correlation. This equation indicates that the MBV also has the ability to classify the plasticity of cohesive soils and the positive correlation with PI:

$$
\mathrm{PI}=e^{(2.525+0.008 \mathrm{MBV})} \quad\left(R^{2}=0.72\right) .
$$

Simultaneously, the relationship between the $\mathrm{P}_{200}$ and MBV was gained according to Figure 3. The data of S2, S11, and S12 were not considered because of their large variability. Equation (4) shows their mathematical formula, which is a good fit:

$$
\mathrm{P}_{200}=44.66 \ln (\mathrm{MBV}+21.73)-115.52 \quad\left(R^{2}=0.79\right) \text {. }
$$

Many studies have reported that the clay mineral is a key factor that affects the suction variation of a soil, and clay minerals are known to have a much higher $\mathrm{P}_{200}$ than other small mineral particles. Thus, as can be seen from the above, $\mathrm{MBV}$ and $\mathrm{P}_{200}$ are positively correlated. It indicates that the higher clay mineral content corresponds to higher MBV for soil sample, since the MBV is positively correlated with $\mathrm{P}_{200}$.

\section{Regression Analysis and Validation}

4.1. Regression Analysis. The SWCCs for 15 cohesive soils were measured by the pressure plate test, which are presented in Figure 4 . The slope of the SWCC in the middle stage represented the suction loss ratio with increasing moisture content in this figure. The steeper suction slopes represent that soil sample is more moisture susceptible. "Moisture susceptibility" describes the rate of loss of subgrade strength, stiffness, and resistance to permanent 
TABLE 2: Testing results.

\begin{tabular}{lcccccccc}
\hline Soil sample & Liquid limit (\%) & Plastic limit $(\%)$ & PI (\%) & $\begin{array}{c}\text { Optimum moisture } \\
\text { content }(\%)\end{array}$ & $\begin{array}{c}\text { Maximum dry } \\
\text { density }\left(\mathrm{g} / \mathrm{cm}^{3}\right)\end{array}$ & $\mathrm{P}_{200}(\%)$ & MBV (mg/g) & Classification \\
\hline S1 & 43.30 & 26.10 & 17.20 & 11.20 & 1.84 & 52.14 & 18.98 \\
S2 & 36.10 & 22.70 & 13.40 & 14.00 & 1.88 & 66.80 & 20.18 \\
S3 & 33.60 & 19.80 & 13.80 & 11.90 & 1.93 & 54.00 & 22.38 & CLS \\
S4 & 35.90 & 19.10 & 16.80 & 11.20 & 1.84 & 51.60 & 27.33 & CLS \\
S5 & 36.60 & 21.50 & 15.10 & 18.90 & 1.68 & 56.50 & 31.87 & CLS \\
S6 & 42.50 & 25.00 & 17.50 & 17.20 & 1.75 & 79.10 & 34.64 & CL \\
S7 & 44.70 & 28.50 & 16.20 & 15.50 & 1.85 & 73.10 & 37.12 & CLS \\
S8 & 42.30 & 22.00 & 20.30 & 14.00 & 1.86 & 59.80 & 38.27 & CLS \\
S9 & 35.80 & 19.30 & 16.50 & 16.00 & 1.92 & 68.70 & 40.45 & CLS \\
S10 & 39.80 & 26.80 & 13.00 & 18.00 & 1.80 & 72.30 & 44.13 & CLS \\
S11 & 35.70 & 16.00 & 19.70 & 11.40 & 1.98 & 64.30 & 54.11 & CLS \\
S12 & 35.80 & 17.00 & 18.80 & 15.50 & 1.84 & 94.20 & 57.34 & CL \\
S13 & 46.10 & 22.10 & 24.00 & 17.00 & 1.84 & 93.10 & 80.33 \\
S14 & 56.50 & 30.10 & 26.40 & 23.50 & 1.56 & 95.08 & 94.00 & CLS \\
S15 & 40.90 & 21.60 & 19.30 & 14.80 & 1.87 & 64.30 & 39.97 \\
\hline
\end{tabular}

Note. $\mathrm{M}$ denotes silt; $\mathrm{C}$ denotes clay; $\mathrm{S}$ denotes soils with sand; $\mathrm{L}$ and $\mathrm{H}$ denote soils with a low liquid limit (no more than $50 \%$ ) and a high liquid limit (larger than $50 \%$ ).

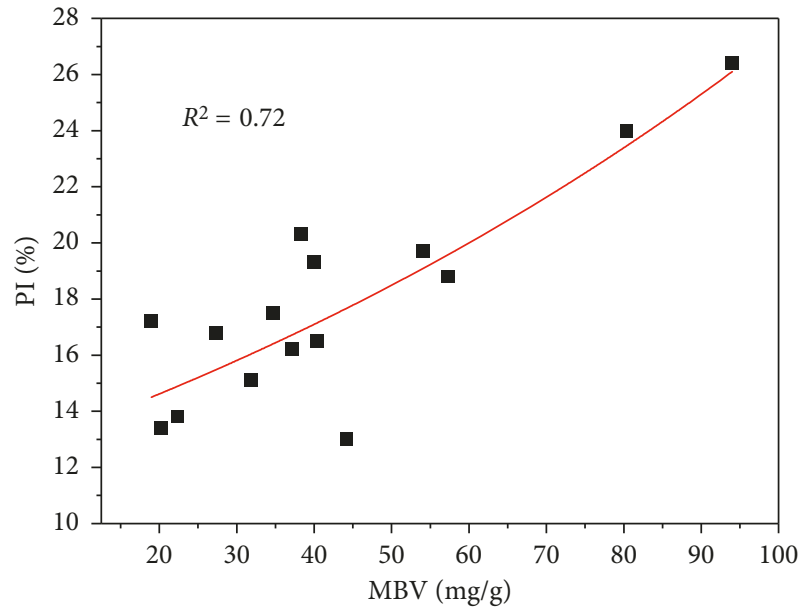

FIgURe 2: Correlation between MBV and PI.

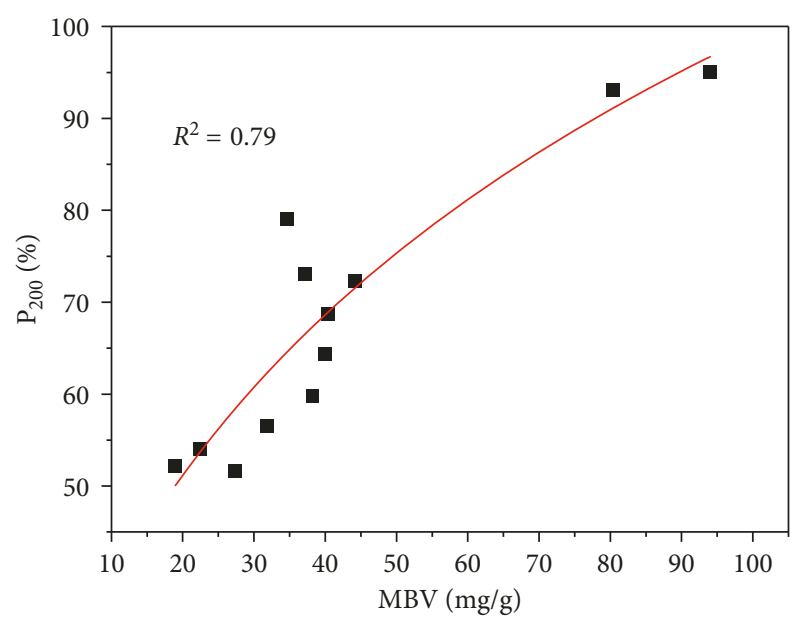

Figure 3: Correlation between $\mathrm{MBV}$ and $\mathrm{P}_{200}$.

deformation with increasing moisture. Therefore, the slope of the SWCCs can also be used to evaluate the moisture susceptibility of subgrade soils. The moisture susceptibility

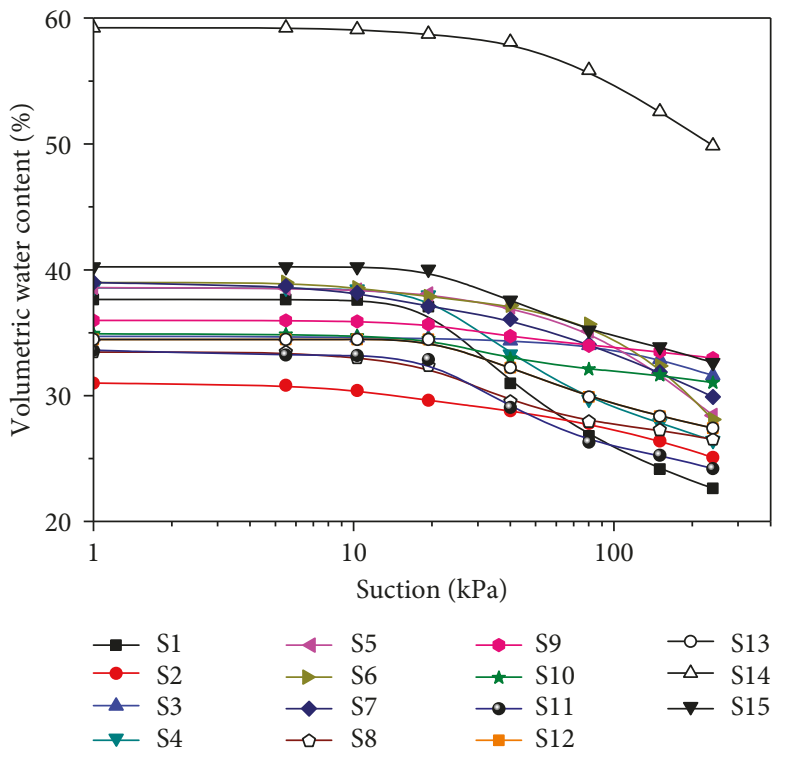

FIgURE 4: SWCCs of cohesive soils.

of the selected soils is ranked as follows: $\mathrm{S} 1>\mathrm{S} 2>\mathrm{S} 3>$ $\mathrm{S} 4>\mathrm{S} 5>\mathrm{S} 6>\mathrm{S} 7>\mathrm{S} 8>\mathrm{S} 15>\mathrm{S} 9>\mathrm{S} 10>\mathrm{S} 11>\mathrm{S} 12>\mathrm{S} 13>\mathrm{S} 14$, according to the comparison of the slope values of SWCCs, as shown in Figure 4.

The four coefficients of Fredlund and Xing's model were gained, according to the results of the pressure plate test, as shown in Table 3.

To investigate the correlation between the four fitting parameters and the $\mathrm{MBV}$, the regression analysis was performed for soil samples S1 S14. In addition, the soil sample S15 was used to validate the rationality of the correlations. Each fitting parameter had a unique equation to describe its relationship with the $\mathrm{MBV}$, as presented in (5)-(8). The air entry value of soil, $a_{\mathrm{f}}$, is formulated in (5). The rate of water extraction of the soil exceeding the air entry value, $b_{\mathrm{f}}$, is formulated based on the MBV given in (6). The mathematical relationship describing the residual 
TABLE 3: Fitting coefficients of Fredlund and Xing's model.

\begin{tabular}{lcccc}
\hline Soil sample & $a_{\mathrm{f}}(\mathrm{kPa})$ & $b_{\mathrm{f}}$ & $c_{\mathrm{f}}$ & $h_{\mathrm{r}}(\mathrm{kPa})$ \\
\hline S1 & 28.55 & 1.28 & 2.72 & 941.39 \\
S2 & 30.86 & 1.26 & 2.67 & 1097.66 \\
S3 & 34.78 & 1.22 & 2.58 & 1361.42 \\
S4 & 42.33 & 1.13 & 2.4 & 1870.75 \\
S5 & 48.15 & 1.06 & 2.24 & 2262.48 \\
S6 & 51.30 & 1.01 & 2.15 & 2474.93 \\
S7 & 53.91 & 0.98 & 2.07 & 2651.18 \\
S8 & 55.07 & 0.96 & 2.04 & 2728.95 \\
S9 & 57.16 & 0.93 & 1.97 & 2870.17 \\
S10 & 60.46 & 0.88 & 1.86 & 3092.12 \\
S11 & 68.17 & 0.76 & 1.60 & 3611.81 \\
S12 & 70.36 & 0.72 & 1.53 & 3759.60 \\
S13 & 83.11 & 0.51 & 1.08 & 4618.98 \\
S14 & 89.05 & 0.42 & 0.88 & 5019.56 \\
S15 & 56.71 & 0.94 & 1.98 & 2839.74 \\
\hline
\end{tabular}

water content of the soil, $c_{\mathrm{f}}$, is given in (7). The mathematical formula describing the suction value at the residual water content, $h_{\mathrm{r}}$, is given in (8):

$$
\begin{aligned}
& a_{\mathrm{f}}=27.4 \ln (\mathrm{MBV}-9.9)-34.7 \quad\left(R^{2}=0.90\right), \\
& b_{\mathrm{f}}=1.66 e^{(-0.014 \mathrm{MBV})} \quad\left(R^{2}=0.72\right), \\
& c_{\mathrm{f}}=0.729 e^{(-0.057 \mathrm{MBV})}+0.12 \quad\left(R^{2}=0.73\right), \\
& h_{\mathrm{r}}=2221.59 \ln (\mathrm{MBV}-4.78)-5024 \quad\left(R^{2}=0.90\right) .
\end{aligned}
$$

According to the above description, (5) and (8) are excellent fits and (6) and (7) are good fits according to the research results of Witczak et al. Those equations can provide a relatively satisfactory correlation. In addition, $a_{\mathrm{f}}$ and $h_{\mathrm{r}}$ have a positive relationship with the MBV, which increase with the increasing MBV. On the other hand, $b_{\mathrm{f}}$ and $c_{\mathrm{f}}$ have a negative relationship with the MBV, which mean that these two fitting coefficients decrease with the increasing MBV. Among the four parameters, $b_{\mathrm{f}}$ is a special one. It represents not only the moisture susceptibility but also the slope of the SWCC.

4.2. Validation. In order to verify the rationality of the prediction method for cohesive soils in this study, the four fitting coefficients of SWCC from the pressure plate test and MBV measured for soil sample S15 were compared, as shown in Table 4. For soil sample S15, the MBV was $39.97 \mathrm{mg} / \mathrm{g}$ and the four fitting coefficients $a_{\mathrm{f}}, b_{\mathrm{f}}, c_{\mathrm{f}}$, and $h_{\mathrm{r}}$ gained from (5)-(8) are 51.06, 0.94, 0.20, and 2839.74, respectively, and they are $51.34,0.95,0.25$, and 2736.15 according to the pressure plate test. Therefore, the difference is negligible for the fitting coefficients between the pressure plate test and new prediction method by the methylene blue test, except the residual suction value $h_{\mathrm{r}}$. However, this difference in the residual suction values will not affect the whole curve of the SWCCs, as shown in Figure 5. It can be seen from Figure 5 that there is a little difference for the initial stage with a low suction, and subsequently, two curves
TABLE 4: Fitting parameters from test and estimation using MBV.

\begin{tabular}{lccccc}
\hline Soil sample S15 & $\begin{array}{c}\mathrm{MBV} \\
(\mathrm{mg} / \mathrm{g})\end{array}$ & $\begin{array}{c}a_{\mathrm{f}} \\
(\mathrm{kPa})\end{array}$ & $b_{\mathrm{f}}$ & $c_{\mathrm{f}}$ & $\begin{array}{c}h_{\mathrm{r}} \\
(\mathrm{kPa})\end{array}$ \\
\hline $\begin{array}{l}\text { Parameters from MBV } \\
\begin{array}{l}\text { Parameters from the } \\
\text { pressure plate test }\end{array}\end{array}$ & 39.97 & 51.06 & 0.94 & 0.20 & 2839.74 \\
\hline
\end{tabular}

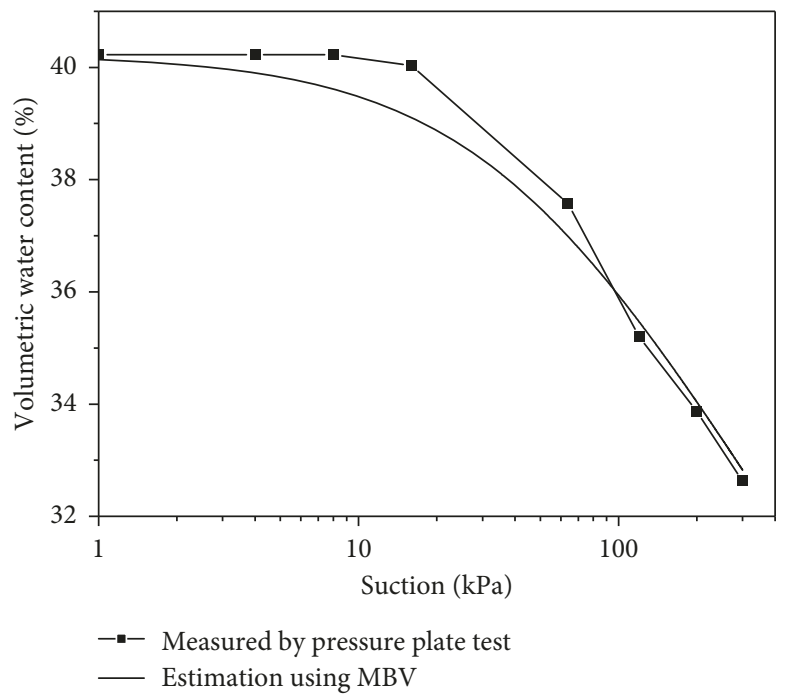

FIGURE 5: SWCCs from test and estimation methods.

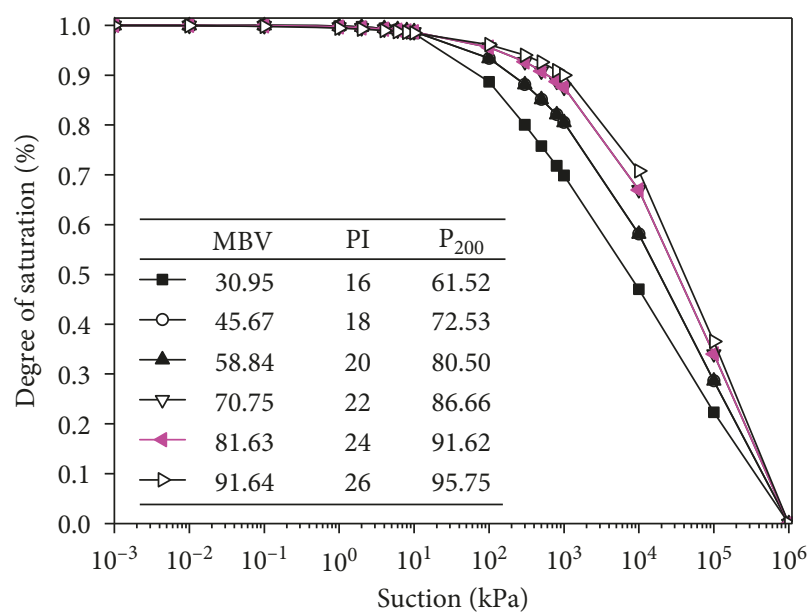

Figure 6: SWCCs with different methylene blue values.

are almost consistent with the increasing suctions. Thus, the accuracy of the prediction method for cohesive soils based on the MBV is acceptable.

\section{SWCCs Predicted Using the Methylene Blue Test}

Figure 6 shows the suction change with the degree of saturation under six different methylene blue values. It is noted that the suction decreases with decreasing MBV under the same degree of saturation; on the other hand, a higher MBV shows a higher suction under the same degree of saturation, 
which means a high moisture-holding capacity. Therefore, the moisture-holding capacity of cohesive soils increases with the increasing MBV.

And at the same time, the four fitting parameters can be expressed in terms of PI and $\mathrm{P}_{200}$, by substituting (3) and (4) into (5)-(8). The PI and $\mathrm{P}_{200}$ values and the corresponding $\mathrm{MBV}$ are also given in Figure 6. Since the MBV has a positive correlation with them, the moisture-holding capacity of cohesive soils increases with the increasing PI and $\mathrm{P}_{200}$. As mentioned above, lower PI or $\mathrm{P}_{200}$ values correspond to lower plasticity soils and higher PI or $\mathrm{P}_{200}$ values are associated with higher plasticity soils, which has the same law reflected in Figure 6.

This study indicates that there is a relationship between the four fitting parameters of Fredlund and Xing's model and the MBV for cohesive soils. The MBV is easy to be measured in a practical engineering. However, the pressure plate test or filter paper, adopted for determining the SWCC, is time-consuming and cost-intensive. Therefore, the four parameters of Fredlund and Xing's model can be predicted by $\mathrm{MBV}$ in a very short time compared to other experimental procedures. And this method can generate the SWCCs for cohesive soils far more efficiently with an acceptable accuracy. Meanwhile, it can even be used in field investigations since the methylene blue test only requires limited portable test equipment.

\section{Conclusions and Discussions}

In order to more effectively determine the MBV for 15 cohesive soils, a new methylene blue test was proved. Then, the mathematical formulations between the four fitting coefficients of Fredlund and Xing's model and the MBV were developed and verified. The major conclusions are drawn as follows:

(1) Compared to other experimental procedures, the new methylene blue test with a colorimeter required fewer experimental tools and soil samples. At the same time, the colorimeter provided an objective way to assess the color change of the methylene blue solution. It greatly reduces the subjective error.

(2) $\mathrm{P}_{200}$ and PI were positively related to MBV, which indicates that the higher clay mineral content corresponds to higher PI or MBV for soil sample.

(3) The fitting parameters $a_{\mathrm{f}}$ and $h_{\mathrm{r}^{\prime}}$ were directly proportional to the MBV, which increase with the increasing $\mathrm{MBV}$, and $b_{\mathrm{f}}$ and $c_{\mathrm{f}}$ were negatively related to the MBV, which means that these two fitting coefficients decrease with the increasing MBV. When the MBV was measured, the four fitting parameters can be calculated using (5)-(8), and its accuracy was proved to be acceptable. It was more efficient to describe the SWCC based on Fredlund and Xing's model by the methylene blue test compared to other experimental procedures.

(4) The slope parameter $b_{f}$ was suitable to evaluate the moisture susceptibility of cohesive soils. Therefore, the MBV can also be used to describe the moisture susceptibility of cohesive soils, which can be gained much more easily and quickly than $b_{\mathrm{f}}$.

(5) It was seen that the correlation coefficients of the mathematical formulations between the four fitting coefficients and the MBV were not high enough. More cohesive soils need to be selected to modify the formulations in the future research. In spite of this, the difference in the results of the pressure plate test and the prediction method using $\mathrm{MBV}$ was acceptable.

\section{Data Availability}

The data used to support the findings of this study are available from the corresponding author upon request.

\section{Conflicts of Interest}

The authors declare that there are no conflicts of interest regarding the publication of this paper.

\section{Acknowledgments}

The authors gratefully acknowledge the financial support of the National Natural Science Foundation of China (51478054), National Key Research and Development Program of China (2017YFC0805307), Excellent Youth Foundation of Natural Science Foundation of Hunan Province of China (2018JJ1026), Key Project of Education Department of Hunan Province (17A008), and Jiangxi Communications Department Program (2013C0011). The study was also supported by the Open Research Fund of Science and Technology Innovation Platform of State Engineering Laboratory of Highway Maintenance Technology, Changsha University of Science \& Technology (kfj150103).

\section{References}

[1] S. Nazari, M. Hassanlourad, E. Chavoshi, and A. Mirzaii, "Experimental investigation of unsaturated silt-sand soil permeability," Advances in Civil Engineering, vol. 2018, Article ID 4946956, 12 pages, 2018.

[2] R. Zhang and J.-L. Zheng, "Study on moisture equilibrium of highway expansive soil embankment," Journal of Highway and Transportation Research and Development, vol. 30, no. 11, pp. 24-32, 2013, in Chinese.

[3] C. W. W. Ng, C. Zhou, Q. Yuan, and J. Xu, "Resilient modulus of unsaturated subgrade soil: Experimental and theoretical investigations," Canadian Geotechnical Journal, vol. 50, no. 2, pp. 223-232, 2013.

[4] M. T. V. Genuchten, "A closed-form equation for predicting the hydraulic conductivity of unsaturated soils," Soil Science Society of America Journal, vol. 44, no. 5, pp. 892-898, 1980.

[5] H. J. Vereecken, J. Maes, J. Feyen, and P. Darius, "Estimating the soil moisture retention characteristic from texture, bulk density, and carbon content," Soil Science, vol. 148, no. 6, pp. 389-403, 1989. 
[6] D. G. Fredlund and A. Xing, "Equations for the soil-water characteristic curve," Canadian Geotechnical Journal, vol. 31, no. 4, pp. 521-532, 1994.

[7] C. E. Zapata, "Uncertainty in soil-water-characteristic curve and impacts on unsaturated shear strength predictions," Ph.D. thesis, Arizona State University, Tempe, AZ, USA, 1999.

[8] Y. Y. Perera, C. E. Zapata, W. N. Houston, and S. L. Houston, "Long-term moisture conditions under highway pavements," in Proceedings of the Geotechnical Engineering for Transportation Projects, pp. 1132-1143, Los Angeles, CA, USA, July 2004.

[9] Y. Y. Perera, C. E. Zapata, W. N. Houston, and S. L. Houston, "Prediction of the soil-water characteristic curve based on grain-size-distribution and index properties," in Proceedings of the Geo-Frontiers Congress, pp. 1-12, Austin, TX, USA, January 2005.

[10] J. Epps, S. Sebesta, B. Hewes, H. Sahin, R. Luo, and J. Button, "Development of a specification for flexible base construction,” Tech. Rep. no. FHWA/TX-13/0-6621, 2014.

[11] H. Sahin, F. Gu, and R. L. Lytton, "Development of soil-water characteristic curve for flexible base materials using the methylene blue test," Journal of Materials in Civil Engineering, vol. 27, no. 5, article 04014175, 2015.

[12] H. Sahin, "Nondestructive test methods for rapid assessment of flexible base performance in transportation infrastructures," Ph.D. thesis, Texas A\&M University, College Station, TX, USA, 2014.

[13] W. N. Houston, H. B. Dye, C. E. Zapata, Y. Y. Perera, and A. Harraz, "Determination of SWCC using one point suction measurement and standard curves," in Proceedings of the Fourth International Conference on Unsaturated Soils, pp. 1482-1493, Carefree, AZ, USA, April 2006.

[14] F. Gu, H. Sahin, X. Luo, R. Luo, and R. L. Lytton, "Estimation of resilient modulus of unbound aggregates using performancerelated base course properties," Journal of Materials in Civil Engineering, vol. 27, no. 6, article 04014188, 2014.

[15] M. D. Fredlund, G. W. Wilson, and D. G. Fredlund, "Use of the grain-size distribution for estimation of the soil-water characteristic curve," Canadian Geotechnical Journal, vol. 39, no. 5, pp. 1103-1117, 2002.

[16] Y. Yukselen and A. Kaya, "Suitability of the methylene blue test for surface area, cation exchange capacity and swell potential determination of clayey soils," Engineering Geology, vol. 102, no. 2, pp. 38-45, 2008.

[17] C. Khengboon, L. Engchoon, and H. Rahardjo, "A simplified method to estimate the soil-water characteristic curve," $\mathrm{Ca}$ nadian Geotechnical Journal, vol. 47, no. 12, pp. 1382-1400, 2010.

[18] X. Li, J. H. Li, and L. M. Zhang, "Predicting bimodal soilwater characteristic curves and permeability functions using physically based parameters," Computers \& Geotechnics, vol. 57, no. 4, pp. 85-96, 2014

[19] ASTM, Standard Test Method for Methylene Blue Index of Clay, ASTM, West Conshohocken, PA, USA, 2009.

[20] J. Xiao, H.-P. Yang, J.-H. Zhang, and X.-Y. Tang, "Surficial failure of expansive soil cutting slope and its flexible support treatment technology," Advances in Civil Engineering, vol. 2018, Article ID 1609608, 13 pages, 2018.

[21] J.-H. Zhang, Q.-P. Jiang, Y.-Q. Zhang, L.-L. Dai, and H.-X. Wu, "Nondestructive measurement of water content and moisture migration of unsaturated red clays in South China," Advances in Materials Science \& Engineering, vol. 2015, Article ID 542538, 7 pages, 2015.
[22] M. W. Witczak, T. K. Pellinen, and M. M. Elbasyouny, "Pursuit of the simple performance test for asphalt concrete fracture/cracking," Journal of the Association of Asphalt Paving Technologists, vol. 71, pp. 767-778, 2002.

[23] A. G. Seferoğlu, M. T. Seferoğlu, and M. V. Akpınar, "Investigation of the effect of recycled asphalt pavement material on permeability and bearing capacity in the base layer," Advances in Civil Engineering, vol. 2018, Article ID 2860213, 6 pages, 2018. 


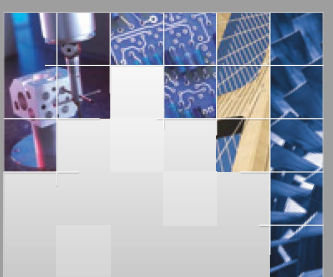

\section{Enfincering}
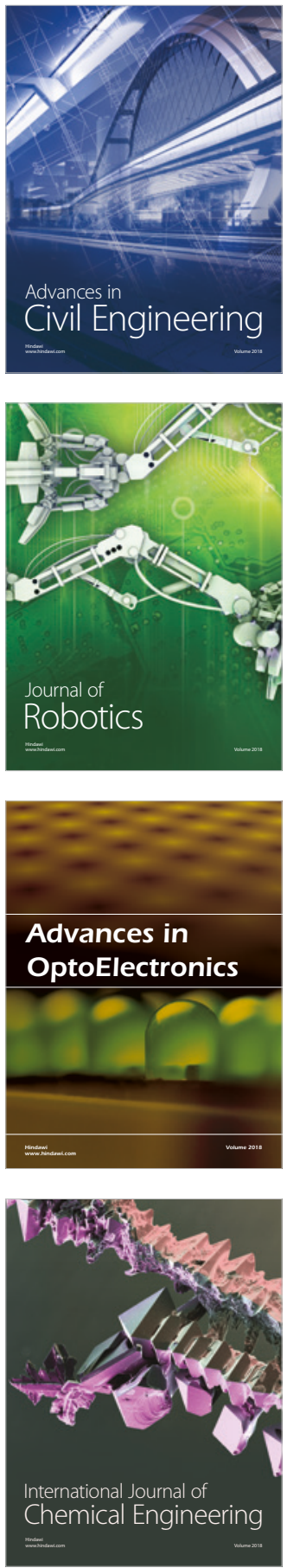

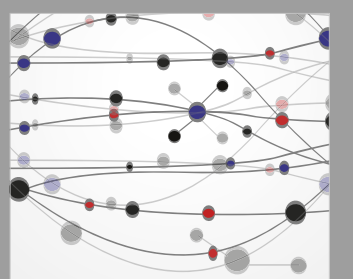

\section{Rotating \\ Machinery}

The Scientific World Journal

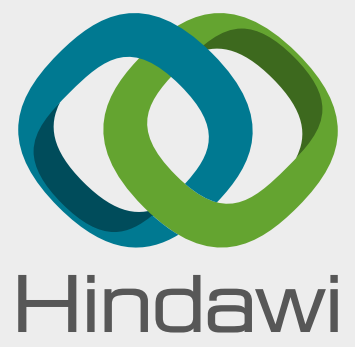

Submit your manuscripts at

www.hindawi.com
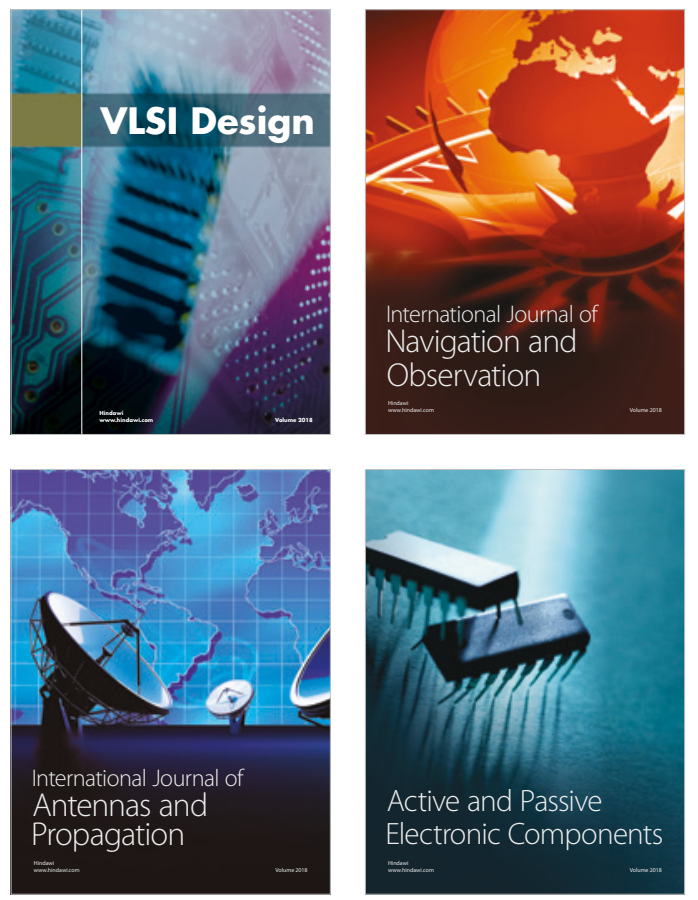
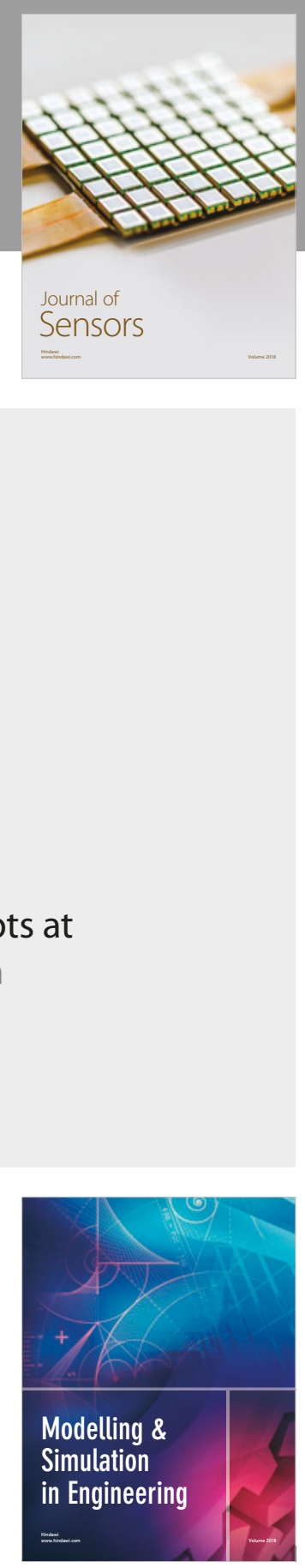

\section{Advances \\ Multimedia}
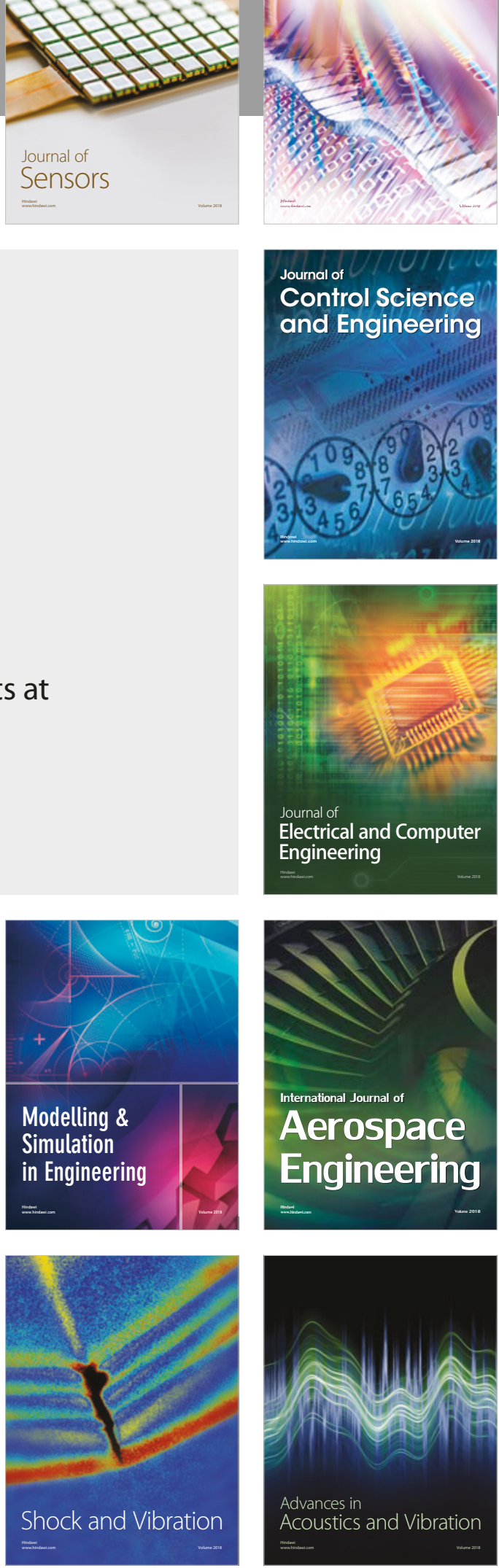